\title{
Experimental Study of Pipes Extrusion Process by Using Method of Coordinate Grids
}

\author{
Kosmatskiy Yaroslav Igorevich ${ }^{1}$, Al-Khuzaie Ahmed Saleem Oleiwi ${ }^{1}$ \\ \& Al-Jumaili Mohammed Jasim Mohammed ${ }^{1}$ \\ ${ }^{1}$ Department of Metal Forming Processes and Machines, Federal State Autonomous Educational Institution of \\ Higher Education, South Ural State University (national research university) (FSAEIHE SUSU (NRU)), Russia \\ Correspondence: Kosmatskiy Yaroslav Igorevich, Department of Metal Forming Processes and Machines, Federal \\ State Autonomous Educational Institution of Higher Education, South Ural State University (national research \\ university) (FSAEIHE SUSU (NRU)), Russia. E-mail: kosmatski@rosniti.ru
}

Received: May 12, 2017

doi:10.5539/jmsr.v7n3p58
Accepted: June 16, 2017

Online Published: June 30, 2018

\begin{abstract}
The paper presents the results of an experimental study of the pipe extrusion process using the method of coordinate grids. The estimation of influence of separate conditions of friction on the contact surfaces of the deformable material and the pressing tool on metal flow pattern. The calculation of the forming operation is made for extrusion process stages.
\end{abstract}

Keywords: extrusion of pipe, method of coordinate grids (MCG), picture of metal flowing, friction conditions, metal forming.

\section{Introduction}

As it is shown in works (Starostin \& Kargin, 1983; Osadchy \& Kolikov, 2012), qualitative characteristics of extruded pipes depend on a number of technological parameters. Among them a strain capacity of a work material (Barichko, Kosmatskiy, \& Rushchits, 2013; Kosmatskiy, Barichko, \& Voskhodov, 2014; Barichko, Kosmatskiy, \& Akhmedyanov, 2015; Kosmatskiy, Fokin, \& Filyaeva, 2016) and friction conditions on contact surfaces, i.e. a deformed metal - a pressing tool (Manegin \& Anisimova, 1978) should be singled out. The studies in the first area are successfully realized due to upsetting tests of cylindrical specimens using a multifunctional complex Gleeble (Barichko, Kosmatskiy, \& Rushchits, 2013; Kosmatskiy, Gaslenko, \& Tikhonova, 2013; Barichko, Kosmatskiy, \& Akhmedyanov, 2015; Kosmatskiy, Fokin, \& Filyaeva, 2016). The rationale for choosing a lubricant on the external and internal surfaces of a deformable material raises an unconventional problem. However, friction conditions specify not only qualitative characteristics of pipes of a finished size, but also the maximum load on a deforming instrument of a pipe extrusion press. Thus, an experimental study of the influence of friction conditions on the pattern of metal flow when pressing pattern pipes can ensure in the initial approximation the formation of a scientific and technology-based approach to selection of lubricants during the pipe extrusion. At the same time, the coordinate grid method (CGM) (Del \& Novikov, 1979; Kargin \& Kargin, 2011) can help justify the choice of boundaries of plastic deformation applied in case of mathematical description of the pipe extrusion process. Besides, the choice in favour of CGM is also justified by the fact that when using it is possible to consider each element of the coordinate grid as an element of the metal flow nucleus undergoing homogeneous strain during the deformation process (Gubkin, 1960).

\section{Method}

The billets ( $\mathrm{C} 1$ grade) 12 quantity and sizes $45 \mathrm{~mm}$ in diameter, $40 \mathrm{~mm}$ long and with a through hole of $9 \mathrm{~mm}$ in diameter were used for physical simulation. The billets were preliminary cut along the centerline in two halves. The coordinate grid consisting of square cells with a way of nearly $5 \mathrm{~mm}$ was applied to each cut surface with the help of the EDM machine (see Figure 1). 


\section{Results}

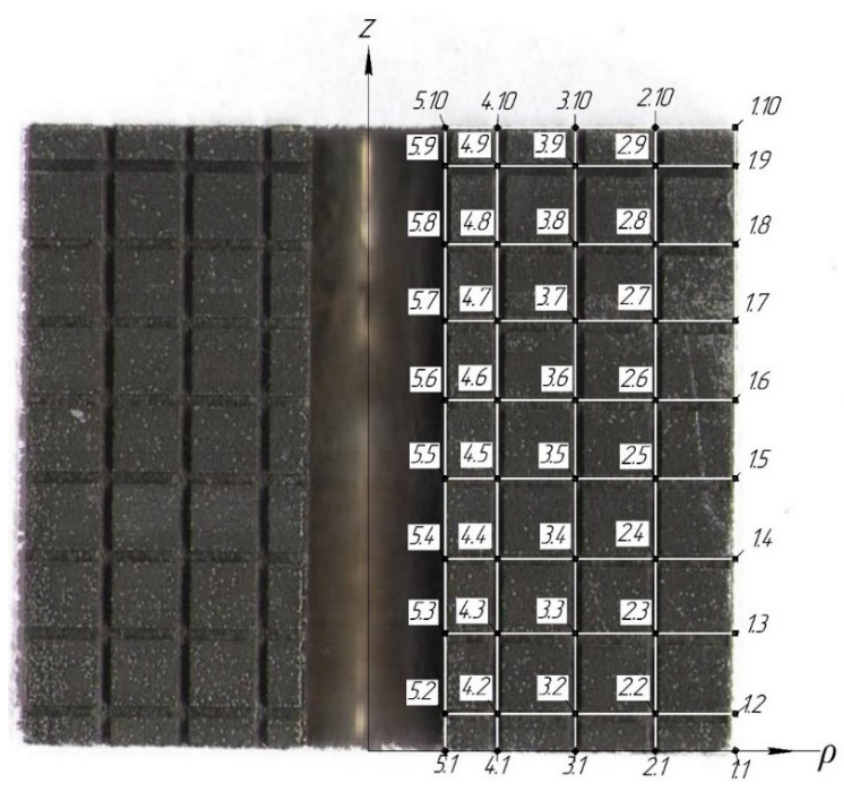

Figure 1. Pattern sleeve with the applied coordinate grid

Table 1. Grid point position of the pattern sleeve: No. of a point $(\rho ; \mathrm{z}), \mathrm{mm}$

\begin{tabular}{lllll}
\hline $1.1(4,9 ; 0)$ & $2.1(8,31 ; 0)$ & $3.1(13,35 ; 0)$ & $4.1(18,53 ; 0)$ & $5.1(23,24 ; 0)$ \\
$1.2(4,9 ; 1,9)$ & $2.2(8,31 ; 1,9)$ & $3.2(13,35 ; 1,9)$ & $4.2(18,53 ; 1,9)$ & $5.2(23,24 ; 1,9)$ \\
$1.3(4,9 ; 6,96)$ & $2.3(8,31 ; 6,96)$ & $3.3(13,35 ; 6,96)$ & $4.3(18,53 ; 6,96)$ & $5.3(23,24 ; 6,96)$ \\
$1.4(4,9 ; 6,96)$ & $2.4(8,31 ; 6,96)$ & $3.4(13,35 ; 6,96)$ & $4.4(18,53 ; 6,96)$ & $5.4(23,24 ; 6,96)$ \\
\hline $1.5(4,9 ; 17,12)$ & $2.5(8,31 ; 17,12)$ & $3.5(13,35 ; 17,12)$ & $4.5(18,53 ; 17,12)$ & $5.5(23,24 ; 17,12)$ \\
$1.6(4,9 ; 22,17)$ & $2.6(8,31 ; 22,17)$ & $3.6(13,35 ; 22,17)$ & $4.6(18,53 ; 22,17)$ & $5.6(23,24 ; 22,17)$ \\
$1.7(4,9 ; 27,26)$ & $2.7(8,31 ; 27,26)$ & $3.7(13,35 ; 27,26)$ & $4.7(18,53 ; 27,26)$ & $5.7(23,24 ; 27,26)$ \\
\hline $1.8(4,9 ; 27,26)$ & $2.8(8,31 ; 27,26)$ & $3.8(13,35 ; 27,26)$ & $4.8(18,53 ; 27,26)$ & $5.8(23,24 ; 27,26)$ \\
$1.9(4,9 ; 37,47)$ & $2.9(8,31 ; 37,47)$ & $3.9(13,35 ; 37,47)$ & $4.9(18,53 ; 37,47)$ & $5.9(23,24 ; 37,47)$ \\
$1.10(4,9 ; 40,5)$ & $2.10(8,31 ; 40,54)$ & $3.10(13,35 ; 40,5)$ & $4.10(18,53 ; 40,54)$ & $5.10(23,24 ; 40,54)$ \\
\hline
\end{tabular}

Subsequently, the billet parts were put together according to a parting plane, previously covered by automobile oil, which protects them from thermal bonding during the extrusion, and jointed together. Using the testing machine by the maximum deformation force of $1.25 \mathrm{MN}$ and corresponding pressing equipment (see Table 2) pattern sleeves were exposed to extrusion in case of production of pattern pipes $25 \times 18 \mathrm{~mm}$ in size according to the following schemes: without lubrication (scheme No. 1); lubrication on the contact surface: a mandrel - an internal surface of the sleeve (scheme No. 2); lubrication on the contact surface: a two-part container liner - an external surface of the sleeve (scheme No. 3); lubrication on all contact surfaces (scheme No. 4).

Table 2. Geometrical parameters of pressing equipment, $\mathrm{mm}$

\begin{tabular}{llll}
\hline Pressing tool & Height & Outer diameter & Inner diameter \\
\hline Mandrel & 95 & 7 & - \\
Pressure pad & 10 & 50 & - \\
\hline Matrix & 6 & 50 & 25 \\
Container liner & 90 & 70 & 50 \\
\hline
\end{tabular}

To reduce a time interval and consequently improve the reliability of experimental data, used for quantitative assessment of a strained condition, we evaluated three positions of the coordinate grid (see Tables $3-5$ ), which correspond to well-known stages (Perlin, 1964) of the extrusion process: pressing out (see Figure 2); steady state (see Figure 3); extrusion process end (see Figures 4 -7). 


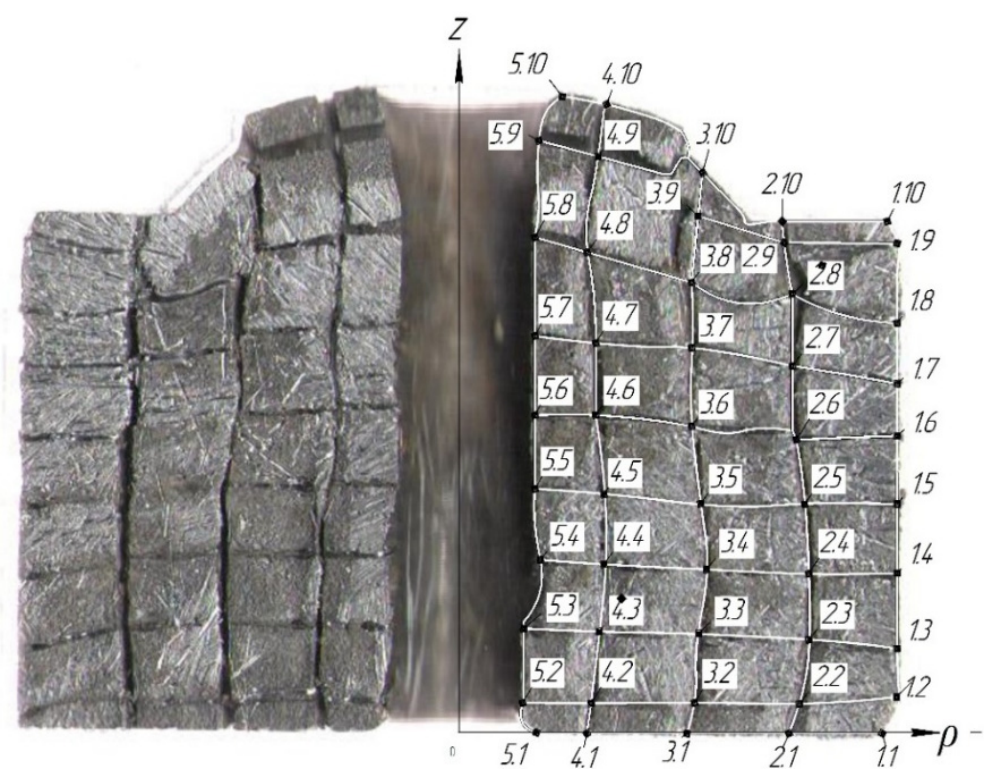

Figure 2. Pressed out pattern sleeve with the applied coordinate grid

(scheme No. 1)

Table 3. Grid point coordinates of the pattern sleeve: No. of a point $(\rho ; z), \mathrm{mm}$

\begin{tabular}{lllll}
\hline $1.1(25,3 ; 0)$ & $2.1(19,42 ; 0)$ & $3.1(13,6 ; 0)$ & $4.1(7,56 ; 0)$ & $5.1(3,69 ; 0)$ \\
$1.2(25,75 ; 2,4)$ & $2.2(20,02 ; 1,69)$ & $3.2(13,84 ; 1,69)$ & $4.2(7,83 ; 1,72)$ & $5.2(3,86 ; 1,89)$ \\
$1.3(25,82 ; 4,7)$ & $2.3(20,62 ; 5,27)$ & $3.3(14,51 ; 5,54)$ & $4.3(8,3 ; 5,74)$ & $5.3(3,69 ; 5,6)$ \\
$1.4(25,84 ; 8,9)$ & $2.4(20,64 ; 8,98)$ & $3.4(14,62 ; 9,22)$ & $4.4(8,5 ; 9,5)$ & $5.4(4,7 ; 9,88)$ \\
\hline $1.5(12,87 ; 25,8)$ & $2.5(20,37 ; 12,8)$ & $3.5(14,27 ; 12,9)$ & $4.5(8,57 ; 13,3)$ & $5.5(4,51 ; 13,6)$ \\
$1.6(25,79 ; 16,3)$ & $2.6(20,02 ; 16,4)$ & $3.6(13,83 ; 16,76)$ & $4.6(8,47 ; 17,5)$ & $5.6(4,5 ; 17,73)$ \\
$1.7(25,99 ; 19,6)$ & $2.7(19,75 ; 20,5)$ & $3.7(13,77 ; 21,63)$ & $4.7(8,13 ; 22,01)$ & $5.7(4,58 ; 22,31)$ \\
\hline $1.8(25,78 ; 23,0)$ & $2.8(19,63 ; 24,55)$ & $3.8(13,72 ; 25,29)$ & $4.8(7,61 ; 26,97)$ & $5.8(4,51 ; 27,8)$ \\
$1.9(25,78 ; 27,4)$ & $2.9(14,14 ; 27,5)$ & $3.9(14,79 ; 29,06)$ & $4.9(9,6 ; 32,37)$ & $5.9(5,5 ; 33,2)$ \\
$1.10(25,2 ; 28,6)$ & $2.10(19,11 ; 28,7)$ & $3.10(13,53 ; 31,4)$ & $4.10(8,72 ; 35,31)$ & $5.10(5,82 ; 35,73)$ \\
\hline
\end{tabular}

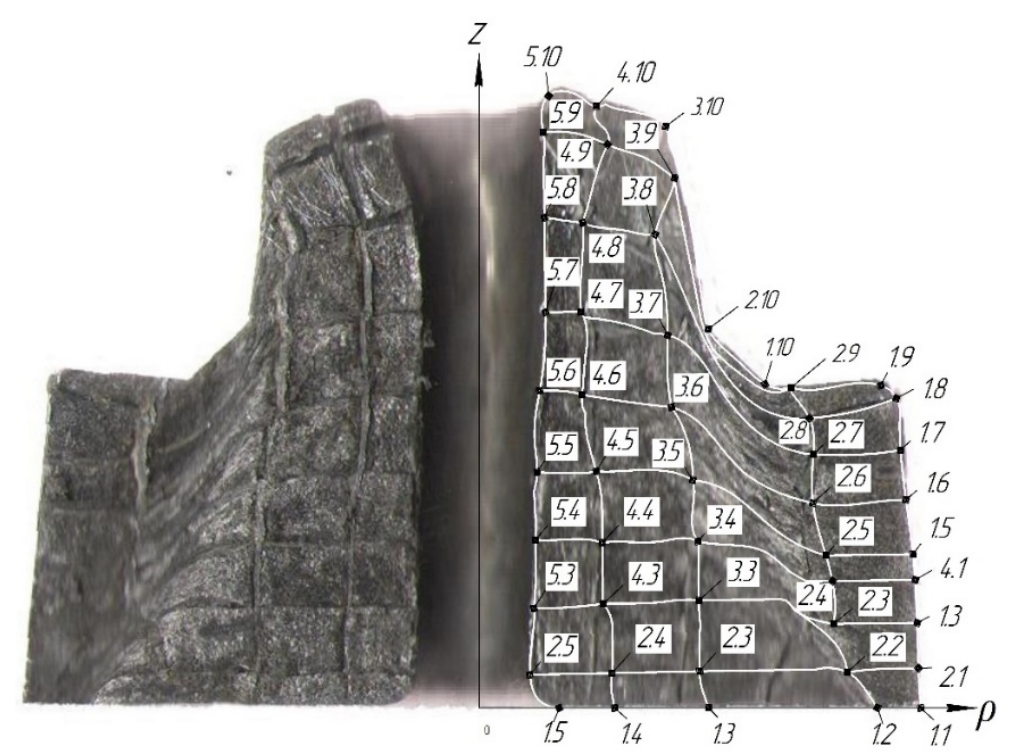

Figure 3. Pattern sleeve with the applied coordinate grid in the steady state (scheme No. 1) 
Table 4. Grid point coordinates of the pattern sleeve in the steady state: No. of a point $(\rho ; z), \mathrm{mm}$

\begin{tabular}{lllll}
\hline $1.1(25 ; 0)$ & $2.1(23,26 ; 0)$ & $3.1(13,5 ; 0)$ & $4.1(7,79 ; 0)$ & $5.1(5,09 ; 0)$ \\
$1.2(24,6 ; 1,85)$ & $2.2(21,94 ; 1,85)$ & $3.2(13,15 ; 1,85)$ & $4.2(7,98 ; 1,7)$ & $5.2(3,7 ; 1,85)$ \\
$1.3(24,2 ; 4,52)$ & $2.3(21,16 ; 4,52)$ & $3.3(13,17 ; 5,78)$ & $4.3(7,47 ; 5,85)$ & $5.3(3,49 ; 5,64)$ \\
$1.4(23,8 ; 6,97)$ & $2.4(19,63 ; 6,97)$ & $3.4(13,17 ; 9,34)$ & $4.4(7,47 ; 9,34)$ & $5.4(3,49 ; 9,54)$ \\
\hline $1.5(23,2 ; 8,44)$ & $2.5(20,76 ; 8,44)$ & $3.5(12,89 ; 12,85)$ & $4.5(7,15 ; 13,43)$ & $5.5(3,34 ; 13,21)$ \\
$1.6(22,8 ; 11,42)$ & $2.6(20,2 ; 11,44)$ & $3.6(11,68 ; 17,03)$ & $4.6(6,37 ; 17,8)$ & $5.6(3,02 ; 18,06)$ \\
$1.7(22,2 ; 14,5)$ & $2.7(20,09 ; 14,22)$ & $3.7(11,5 ; 21,15)$ & $4.7(6,41 ; 22,55)$ & $5.7(3,19 ; 22,55)$ \\
\hline $1.8(22,3 ; 18,68)$ & $2.8(19,81 ; 17,23)$ & $3.8(10,83 ; 26,91)$ & $4.8(6,53 ; 27,62)$ & $5.8(3,57 ; 28,02)$ \\
$1.9(21,9 ; 19,35)$ & $2.9(18,33 ; 18,93)$ & $3.9(12,03 ; 30,12)$ & $4.9(8,07 ; 32,08)$ & $5.9(5,07 ; 33,04)$ \\
$1.10(16,94 ; 18,8)$ & $2.10(13,39 ; 22,18)$ & $3.10(12,28 ; 32,22)$ & $4.10(8,51 ; 33,72)$ & $5.10(5,9 ; 34,71)$ \\
\hline
\end{tabular}

When considering the coordinate grids (see Figures $4-7$ ) the following conclusions can be made:

- a hypothesis about the flow non-uniformity in case of correct pressing;

- the maximum speed differential of longitudinal movements is observed in the area before an exit from the deformation zone. When the metal moves towards the exit from the deformation zone, the deformation speed becomes balanced.

- near the contact surface of the deformed metal with the mandrel grids are deformed for a smaller value, as compared to the zone of a matrix funnel, where deformation has a larger value;

- in the matrix funnel zone, where deformation has a larger value, the quality of the coordinate grid is unsatisfactory and difficult to replicate. In case of large values of deformation degrees the use of CGM is unacceptable.

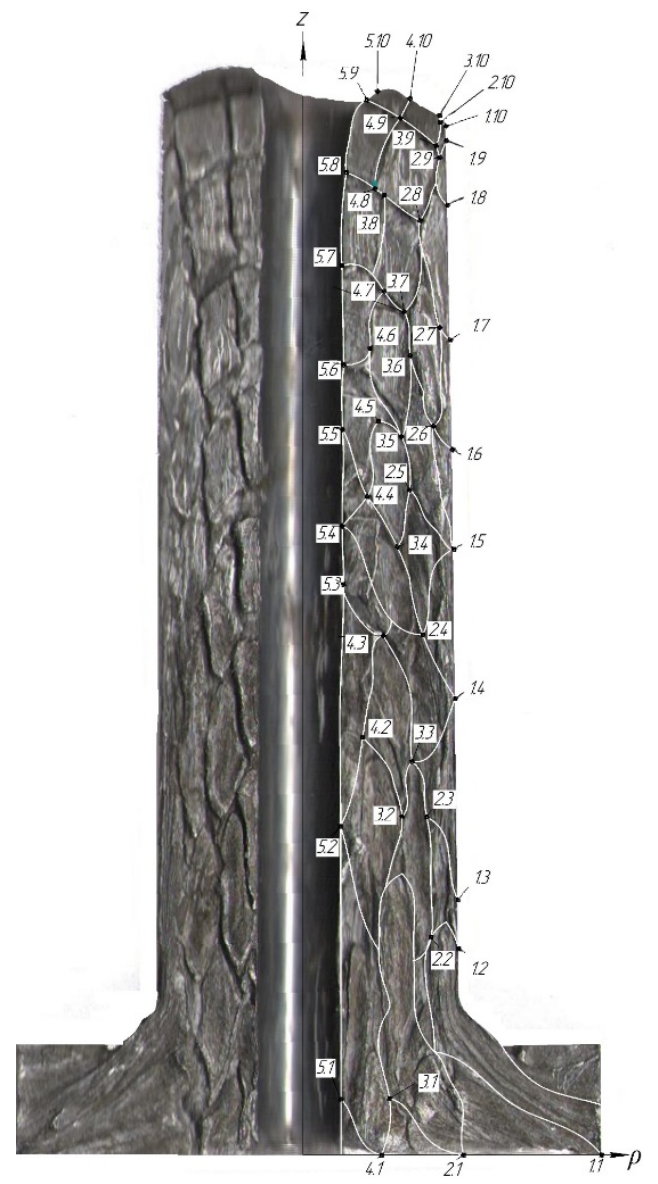

Figure 4. Pattern pipe with the applied coordinate grid (scheme No. 1)

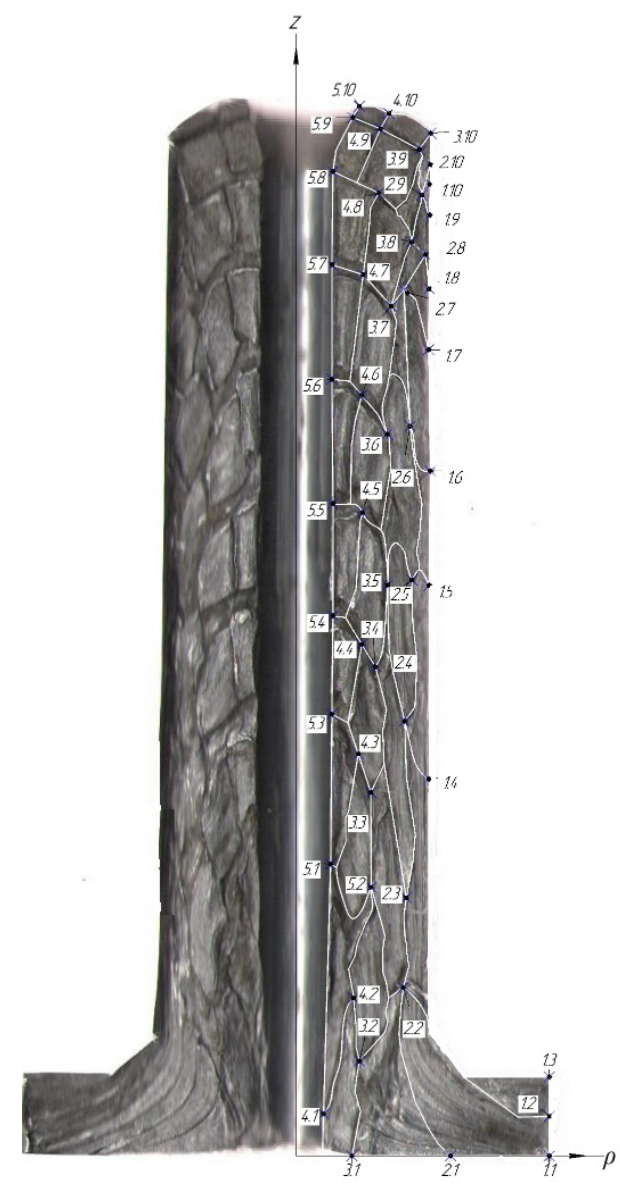

Figure 5. Pattern pipe with the applied coordinate grid (scheme No. 2) 


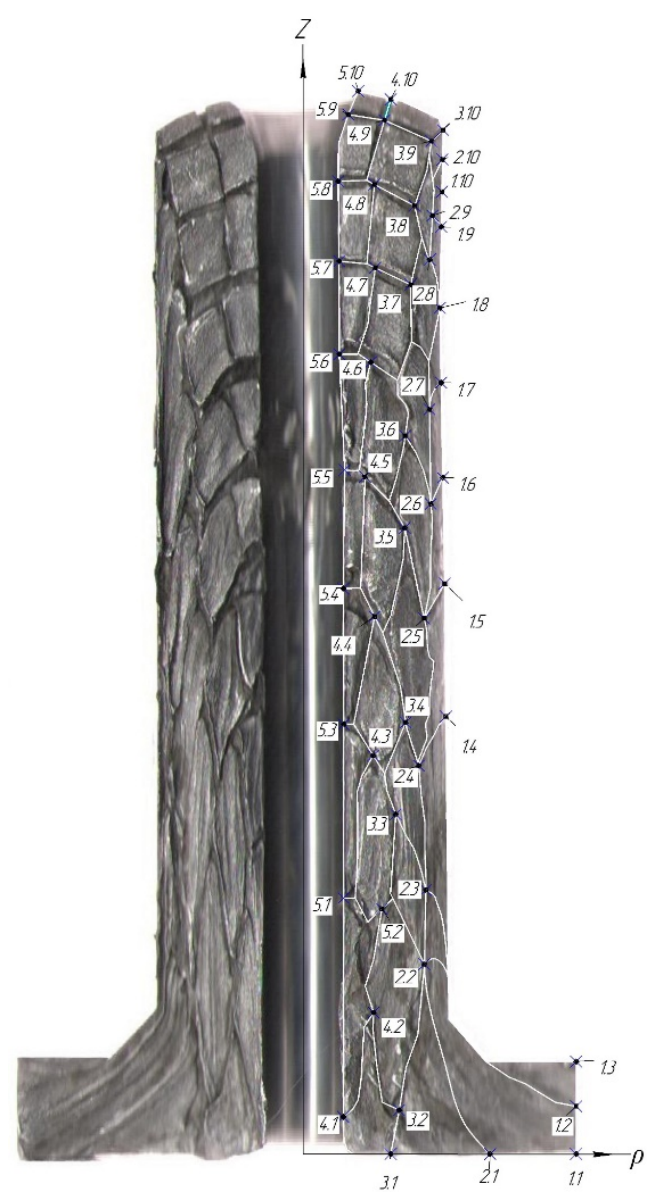

Figure 6. Pattern pipe with the applied coordinate grid (scheme No. 3)

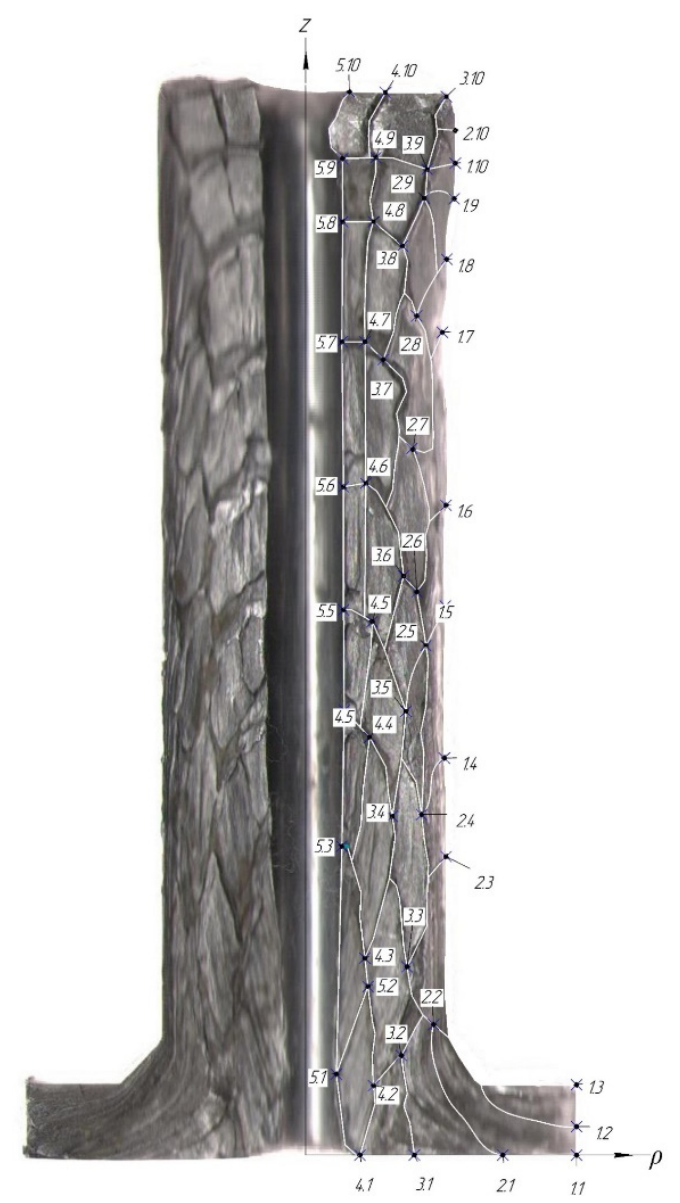

Figure 7. Pattern pipe with the applied coordinate grid (scheme No. 4)

It is commonly known (Siebel, 1934) that the stress of contact friction $\left(\tau_{K}\right)$ is defined by Siebel's formula:

$$
\tau_{K}=\mu \sigma_{S}
$$

The work of deformation can be defined as:

$$
A_{\Phi}=\sigma_{S} \iiint_{\mathrm{V}} \varepsilon_{H} d V
$$

where $\sigma_{S}$ is a value of metal resistance to plastic shear strain; $\varepsilon_{U}$ is a strain intensity; $\mathrm{V}$ is the volume of metal where deformation happens.

The strain intensity $\left(\varepsilon_{U}\right)$ is calculated according to the formula (Kolmogorov, 1986):

$$
\varepsilon_{И}=\frac{\sqrt{2}}{3} \sqrt{\left(\varepsilon_{\rho}-\varepsilon_{\varphi}\right)^{2}+\left(\varepsilon_{\varphi}-\varepsilon_{Z}\right)^{2}+\left(\varepsilon_{Z}-\varepsilon_{\rho}\right)^{2}+\frac{3}{2}\left(\gamma_{\rho \varphi}^{2}+\gamma_{\rho Z}^{2}+\gamma_{Z \varphi}^{2}\right)},
$$

where $\varepsilon_{\rho}, \varepsilon_{\varphi}, \varepsilon_{Z}$ is a normal component of the strain intensity; $\gamma$ is a tangential component of the strain intensity.

During extrusion there is a non-uniform plastic flow and a value of the strain intensity is different at different points of the deformation zone. Thus, for determination of deformation work we should specify the strain intensity (7), as a function, the volume integral of which, can be used for calculation of deformation work. The analytical determination of the deformation field is not a trivial task. That's why in this case the CGM is applied to determine the deformation strain. 
Table 5. Grid point coordinates of the pattern pipe: No. of a point $(\rho ; \mathrm{z}), \mathrm{mm}$

\begin{tabular}{|c|c|c|c|c|}
\hline \multicolumn{5}{|c|}{ Scheme No. 1 (see Fig. 4) } \\
\hline $1.1(25,0 ; 0)$ & $2.1(14,2 ; 0)$ & $3.1(11,79 ; 8,92)$ & $4.1(6,93 ; 0)$ & $5.1(3,43 ; 4,85)$ \\
\hline $1.2(19,11 ; 18,04)$ & $2.2(11,07 ; 19,1)$ & $3.2(9,23 ; 29,86)$ & $4.2(5,79 ; 36,97)$ & $5.23(3,79 ; 29,12)$ \\
\hline $1.3(14,14 ; 22,41)$ & $2.3(11,44 ; 29,78)$ & $3.3(10,17 ; 34,75)$ & $4.3(7,59 ; 45,97)$ & $5.3(4,05 ; 49,96)$ \\
\hline $1.4(14,01 ; 40,27)$ & $2.4(11,09 ; 45,97)$ & $3.4(8,77 ; 53,83)$ & $4.4(6,05 ; 58,36)$ & $5.4(3,86 ; 55,79)$ \\
\hline $1.5(13,55 ; 53,46)$ & $2.5(9,78 ; 58,87)$ & $3.5(9,03 ; 63,54)$ & $4.5(6,94 ; 65,02)$ & $5.5(3,77 ; 64,34)$ \\
\hline $1.6(12,1 ; 62,38)$ & $2.6(11,81 ; 64,49)$ & $3.6(9,65 ; 70,47)$ & $4.6(6,05 ; 71,48)$ & $5.6(3,76 ; 70,09)$ \\
\hline $1.7(12,14 ; 72,11)$ & $2.7(12,18 ; 73,23)$ & $3.7(8,98 ; 74,72)$ & $4.7(6,09 ; 78,06)$ & $5.7(3,35 ; 78,92)$ \\
\hline $1.8(12,56 ; 84,1)$ & $2.8(10,17 ; 82,79)$ & $3.8(6,91 ; 85,09)$ & $4.8(6,07 ; 85,68)$ & $5.8(3,46 ; 87,17)$ \\
\hline $1.9(12,24 ; 89,83)$ & $2.9(11,73 ; 88,33)$ & $3.9(11,36 ; 89,4)$ & $4.9(8,08 ; 91,93)$ & $5.9(5,06 ; 93,58)$ \\
\hline $1.10(12,16 ; 91,14)$ & $2.10(11,66 ; 91,48)$ & $3.10(11,56 ; 92,07)$ & $4.10(8,89 ; 93,62)$ & $5.10(5,97 ; 94,33)$ \\
\hline \multicolumn{5}{|c|}{ Scheme No. 2 (see Fig. 5) } \\
\hline $1.1(24,0 ; 0)$ & $2.1(14,6 ; 0)$ & $3.1(5,2 ; 0)$ & $4.1(2,6 ; 4,0)$ & $5.1(3,2 ; 27,80)$ \\
\hline $1.2(24,0 ; 3,76)$ & $2.2(10,16 ; 16,05)$ & $3.2(6,0 ; 9,05)$ & $4.2(5,44 ; 15,06)$ & $5.2(7,11 ; 25,60)$ \\
\hline $1.3(24,0 ; 7,52)$ & $2.3(10,45 ; 24,61)$ & $3.3(7,09 ; 34,64)$ & $4.3(5,88 ; 38,31)$ & $5.3(3,38 ; 42,10)$ \\
\hline $1.4(12,58 ; 35,91)$ & $2.4(10,3 ; 41,44)$ & $3.4(7,51 ; 46,53)$ & $4.4(6,22 ; 48,76)$ & $5.4(3,5 ; 51,49)$ \\
\hline $1.5(12,6 ; 54,39)$ & $2.5(10,97 ; 54,89)$ & $3.5(8,69 ; 54,41)$ & $4.5(6,29 ; 61,31)$ & $5.5(3,51 ; 62,18)$ \\
\hline $1.6(12,73 ; 65,29)$ & $2.6(10,8 ; 69,55)$ & $3.6(8,65 ; 68,79)$ & $4.6(6,23 ; 72,5)$ & $5.6(3,4 ; 74,04)$ \\
\hline $1.7(12,57 ; 76,85)$ & $2.7(10,23 ; 82,6)$ & $3.7(9,02 ; 81,02)$ & $4.7(6,36 ; 84,0)$ & $5.7(3,4 ; 84,91)$ \\
\hline $1.8(12,61 ; 82,66)$ & $2.8(12,27 ; 85,78)$ & $3.8(10,96 ; 87,12)$ & $4.8(7,83 ; 91,78)$ & $5.8(3,48 ; 93,84)$ \\
\hline $1.9(12,67 ; 89,69)$ & $2.9(11,9 ; 91,59)$ & $3.9(11,67 ; 95,94)$ & $4.9(7,99 ; 97,90)$ & $5.9(5,38 ; 98,99)$ \\
\hline $1.10(12,7 ; 92,62)$ & $2.10(12,73 ; 94,5)$ & $3.10(12,76 ; 97,49)$ & $4.10(8,82 ; 99,38)$ & $5.10(5,99 ; 100,0)$ \\
\hline \multicolumn{5}{|c|}{ Scheme No. 3 (see Fig. 6) } \\
\hline $1.1(23,82 ; 0)$ & $2.1(16,28 ; 0)$ & $3.1(7,62 ; 0)$ & $4.1(3,5 ; 3,25)$ & $5.1(3,53 ; 22,43)$ \\
\hline $1.2(23,79 ; 4,17)$ & $2.2(10,56 ; 16,62)$ & $3.2(8,36 ; 3,85)$ & $4.2(6,14 ; 12,4)$ & $5.2(6,85 ; 21,47)$ \\
\hline $1.3(23,79 ; 8,09)$ & $2.3(10,68 ; 23,13)$ & $3.3(8,06 ; 29,75)$ & $4.3(6,1 ; 34,91)$ & $5.3(3,53 ; 37,64)$ \\
\hline $1.4(12,44 ; 38,31)$ & $2.4(10,07 ; 34,02)$ & $3.4(8,93 ; 37,81)$ & $4.4(6,22 ; 47,08)$ & $5.4(3,5 ; 49,54)$ \\
\hline $1.5(12,33 ; 49,47)$ & $2.5(10,54 ; 46,91)$ & $3.5(8,84 ; 54,84)$ & $4.5(5,38 ; 59,33)$ & $5.5(3,61 ; 59,9)$ \\
\hline $1.6(12,17 ; 59,25)$ & $2.6(11,12 ; 56,94)$ & $3.6(8,89 ; 62,9)$ & $4.6(5,89 ; 69,35)$ & $5.6(3,15 ; 70,06)$ \\
\hline $1.7(12,02 ; 67,65)$ & $2.7(11,0 ; 65,22)$ & $3.7(9,36 ; 76,14)$ & $4.7(6,29 ; 77,62)$ & $5.7(3.13 ; 78,21)$ \\
\hline $1.8(11,92 ; 74,10)$ & $2.8(11,03 ; 78,34)$ & $3.8(9,71 ; 83,01)$ & $4.8(6,21 ; 84,92)$ & $5.8(3,05 ; 85,2)$ \\
\hline $1.9(12,93 ; 81,21)$ & $2.9(11,26 ; 82,19)$ & $3.9(11,17 ; 88,72)$ & $4.9(7,08 ; 90,55)$ & $5.9(3,92 ; 91,01)$ \\
\hline $1.10(12,08 ; 84,29)$ & $2.10(12,13 ; 87,11)$ & $3.10(12,17 ; 89,9)$ & $4.10(7,63 ; 92,39)$ & $5.10(4,79 ; 93,11)$ \\
\hline \multicolumn{5}{|c|}{ Scheme No. 4 (see Fig. 7) } \\
\hline $1.1(24,67 ; 0)$ & $2.1(17,94 ; 0)$ & $3.1(9,89 ; 0)$ & $4.1(4,93 ; 0)$ & $5.1(2,77 ; 7,41)$ \\
\hline $1.2(24.61 ; 2,61)$ & $2.2(11,64 ; 11,96)$ & $3.2(8,7 ; 9.11)$ & $4.2(6,16 ; 6,35)$ & $5.2(5,66 ; 15,43)$ \\
\hline $1.3(24,66 ; 6,43)$ & $2.3(12,77 ; 27,33)$ & $3.3(9,22 ; 17,24)$ & $4.3(5,37 ; 18,02)$ & $5.3(3.28 ; 28,26)$ \\
\hline $1.4(12,61 ; 36,34)$ & $2.4(10,54 ; 31,18)$ & $3.4(7,88 ; 31,0)$ & $4.4(5,8 ; 38,25)$ & $5.4(3,5 ; 40,72)$ \\
\hline $1.5(12,71 ; 50,27)$ & $2.5(10,94 ; 46,62)$ & $3.5(9.12 ; 40,61)$ & $4.5(6,04 ; 48,83)$ & $5.5(3,43 ; 49,91)$ \\
\hline $1.6(12,78 ; 59,48)$ & $2.6(10,11 ; 51,55)$ & $3.6(8,91 ; 53,02)$ & $4.6(5,46 ; 61,5)$ & $5.6(3,42 ; 61,17)$ \\
\hline $1.7(12,45 ; 75,31)$ & $2.7(9,76 ; 64,59)$ & $3.7(7,05 ; 72,82)$ & $4.7(5,38 ; 74,45)$ & $5.7(3,23 ; 74,45)$ \\
\hline $1.8(12,84 ; 82,0)$ & $2.8(10,09 ; 76,81)$ & $3.8(8,8 ; 83,22)$ & $4.8(6,15 ; 84,44)$ & $5.8(3,36 ; 85,43)$ \\
\hline $1.9(13,51 ; 87,53)$ & $2.9(10,78 ; 87,58)$ & $3.9(11,06 ; 90,22)$ & $4.9(6,39 ; 91,3)$ & $5.9(3,34 ; 91,22)$ \\
\hline $1.10(13,62 ; 90,78)$ & $2.10(13,62 ; 93,79)$ & $3.10(12,8 ; 96,87)$ & $4.10(7,26 ; 97,26)$ & $5.10(3,95 ; 97,34)$ \\
\hline
\end{tabular}

\section{Discussion}

To find the strain intensity the components of a deformation tensor should be specified. Therefore, from the plasticity theory (Thomsen, Yang, \& Kobayashi, 1969; Kolmogorov, 1986) it is known: 


$$
\left\{\begin{array}{l}
\varepsilon_{Z}=\frac{\partial u_{Z}}{\partial z} \\
\varepsilon_{\rho}=\frac{\partial u_{\rho}}{\partial \rho} \\
\varepsilon_{\varphi}=\frac{u_{\rho}}{\rho}+\frac{1}{\rho} \frac{\partial u_{\varphi}}{\partial \varphi} \\
\gamma_{\rho Z}=\frac{\partial u_{Z}}{\partial \rho}+\frac{\partial u_{\rho}}{\partial z} \\
\gamma_{\varphi Z}=\frac{1}{\rho} \frac{\partial u_{Z}}{\partial \varphi}+\frac{\partial u_{\varphi}}{\partial z} \\
\gamma_{\rho \varphi}=\rho \frac{\partial\left(u_{\varphi} / \rho\right)}{\partial \rho}+\frac{1}{\rho} \frac{\partial u_{\rho}}{\partial \varphi}
\end{array},\right.
$$

where $u$ is displacement of elementary volume.

The metal doesn't flow in a circular motion around an axis of pressing, i.e. displacement: $\partial u_{\varphi}=0$. As the process is axially symmetrical, the displacement of points and deformation doesn't depend on the $\varphi$ coordinate. As for derivative determination, a derivative of the constant value is equal to 0 (Fikhtengolts, 2001), namely:

$$
\left\{\begin{array}{l}
\frac{\partial u_{\varphi}}{\partial \varphi}=0 \\
\frac{\partial u_{Z}}{\partial \varphi}=0 \\
\frac{\partial u_{\rho}}{\partial \varphi}=0
\end{array}\right.
$$

Based on the abovementioned, deformation degrees can be defined by formulas:

$$
\left\{\begin{array}{l}
\varepsilon_{Z}=\frac{\partial u_{Z}}{\partial z} \\
\varepsilon_{\rho}=\frac{\partial u_{\rho}}{\partial \rho} \\
\varepsilon_{\varphi}=\frac{u_{\rho}}{\rho} \\
\gamma_{\rho Z}=\frac{\partial u_{Z}}{\partial \rho}+\frac{\partial u_{\rho}}{\partial z} \\
\gamma_{\varphi Z}=0 \\
\gamma_{\rho \varphi}=0
\end{array},\right.
$$

To specify the components of strain intensity coordinates of all points before $\left(z_{i j}^{\text {нач }}, \rho_{i j}^{\text {нач }}\right)$ and after deformation $\left(z_{i j}, \rho_{i j}\right)$ should be defined. After that it is not difficult to determine the average values of height, width and radius of cells, respectively: 


$$
\begin{gathered}
h_{i j}=\frac{z_{i+1, j}-z_{i, j}+z_{i+1, j+1}-z_{i, j+1}}{2} ; \\
s_{i j}=\frac{\rho_{i, j}-\rho_{i, j+1}+\rho_{i+1, j}-\rho_{i+1, j+1}}{2} ; \\
\rho_{i j}=\sqrt[4]{\rho_{i, j} \cdot \rho_{i+1, j} \cdot \rho_{i, j+1} \cdot \rho_{i+1, j+1}} .
\end{gathered}
$$

For each cell we define the values of four angles $\left(\varphi_{i, j, k}\right)$, applying a relevant formula for determination of angles between vectors $\vec{a}$ and $\vec{b}$, where $k$ is an angle number in the cell:

$$
\varphi=\arccos \left(\frac{x_{a} x_{b}+y_{a} y_{b}}{|\vec{a}| \cdot|\vec{b}|}\right)
$$

The diagram for determination of values reflected in the formulas (11-14) is shown in Figure 8.

According to Figure 8, the cell height can be specified using the formula:

$$
h_{i j}=\frac{H_{i, j, \pi}+H_{i, j, \Pi}}{2},
$$

where $H_{i, j, \text { Левое }}=z_{i+1, j}-z_{i, j}, H_{i, j, \text { Правое }}=z_{i+1, j+1}-z_{i, j+1}$.

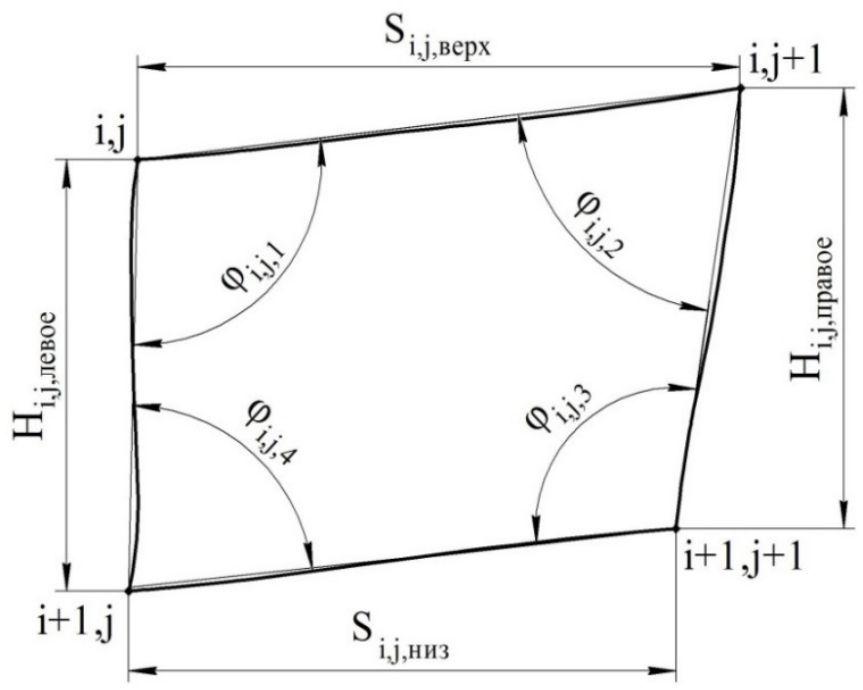

Figure 8. Design model of the deformed cell

After that the deformation degrees are defined: 


$$
\left\{\begin{array}{l}
\varepsilon_{Z}=\ln \left(\frac{h_{i j}}{h_{0 i j}}\right) \\
\varepsilon_{\rho}=\ln \left(\frac{r_{i j}}{r_{0 i j}}\right) \\
\varepsilon_{\varphi}=\ln \left(\frac{s_{i j}}{s_{0 i j}}\right) \\
\gamma_{\rho Z}=\frac{\left(\ln \left(\frac{\varphi_{i, j, 1} \varphi_{i, j, 3}}{\varphi_{0 i, j, 1} \varphi_{i, j, 3}}\right)+\ln \left(\frac{\varphi_{i, j, 2} \varphi_{i, j, 4}}{\varphi_{0 i, j, 2} \varphi_{i, j, 4}}\right)\right)}{2}
\end{array},\right.
$$

Whereupon, using the dependency (7), the stain intensity $\left(\varepsilon_{U}\right)$ is specified.

As a result, having the information about the strain intensity, it is possible to define the deformation work in each cell:

$$
A_{\Phi}=\pi \sigma_{S} \cdot \varepsilon_{U i, j} \cdot s_{i, j} \cdot h_{i, j} \cdot\left(2 \rho_{\max _{i, j}}-s_{i, j}\right),
$$

where $\rho_{\text {max }_{i, j}}$ is a maximum cell radius:

$$
\rho_{\max _{i, j}}=\frac{\rho_{i, j}+\rho_{i+1, j}}{2} .
$$

Using the results of coordinate measuring of the coordinate grid nodes, given in Tables $1,3-5$, we performed calculation of deformation work when manufacturing pattern pipes $25 \times 18 \mathrm{~mm}$ in size in accordance to the following schemes: without lubrication (scheme No. 1, see Figure 4); with lubrication on the contact surface: a mandrel - an internal surface of the sleeve (scheme No. 2, see Figure 5); with lubrication on the contact surface: a two-part container liner - an external surface of the sleeve (scheme No. 3, see Figure 6); with lubrication on all contact surfaces (scheme No. 4, see Figure 7). The calculation results are shown in Table 6.

Table 6. Calculation results of deformation work, $\mathrm{kJ}$

\begin{tabular}{ccccc}
\hline Extrusion process stages & Scheme No. 1 & Scheme No. 2 & Scheme No. 3 & Scheme No. 4 \\
\hline Sleeve pressing out & 0,42 & 0,42 & 0,42 & 0,42 \\
Steady-state process & 0,32 & 0,28 & 0,23 & 0,19 \\
\hline Process end & 2,40 & 1,92 & 1,77 & 1,76 \\
\hline
\end{tabular}

The conducted experimental study of pipe extrusion process using the CGM under different friction conditions on the contact surfaces of the deformed metal and the pressing tool has enabled us to draw the following conclusions:

- it is obvious that deformation proceeds non-uniformly. At the same time when creating favourable conditions on the contact surfaces owing to lubricants (see Figures $5-7$ ), the deformed sample is distinguished by uniformity of distribution of the coordinate grid over the wall thickness of a pattern pipe.

- according to Figures $3-7$, the deformed sample has a stagnant zone of metal, geometrically similar to designated zones in case of mathematical simulation of the pipe extrusion process. For illustration purposes, Fig. 9 shows a fragment ( $1 / 4$ part) of pattern pressing residue formed as a result of pipe extrusion on the pipe extrusion press, $20 \mathrm{MN}$ stress, in the context of Volzhsky Pipe Plant applying a pressure pad of new shaping. As you can see, according to Figure 9, porosity and a fiber structure in the area of press tightening is observed in the macrostructure of pressing residue. In addition, the macrostructure of metal in the contact area with the matrix and the mandrel has a sophisticated fine-grained structure. 


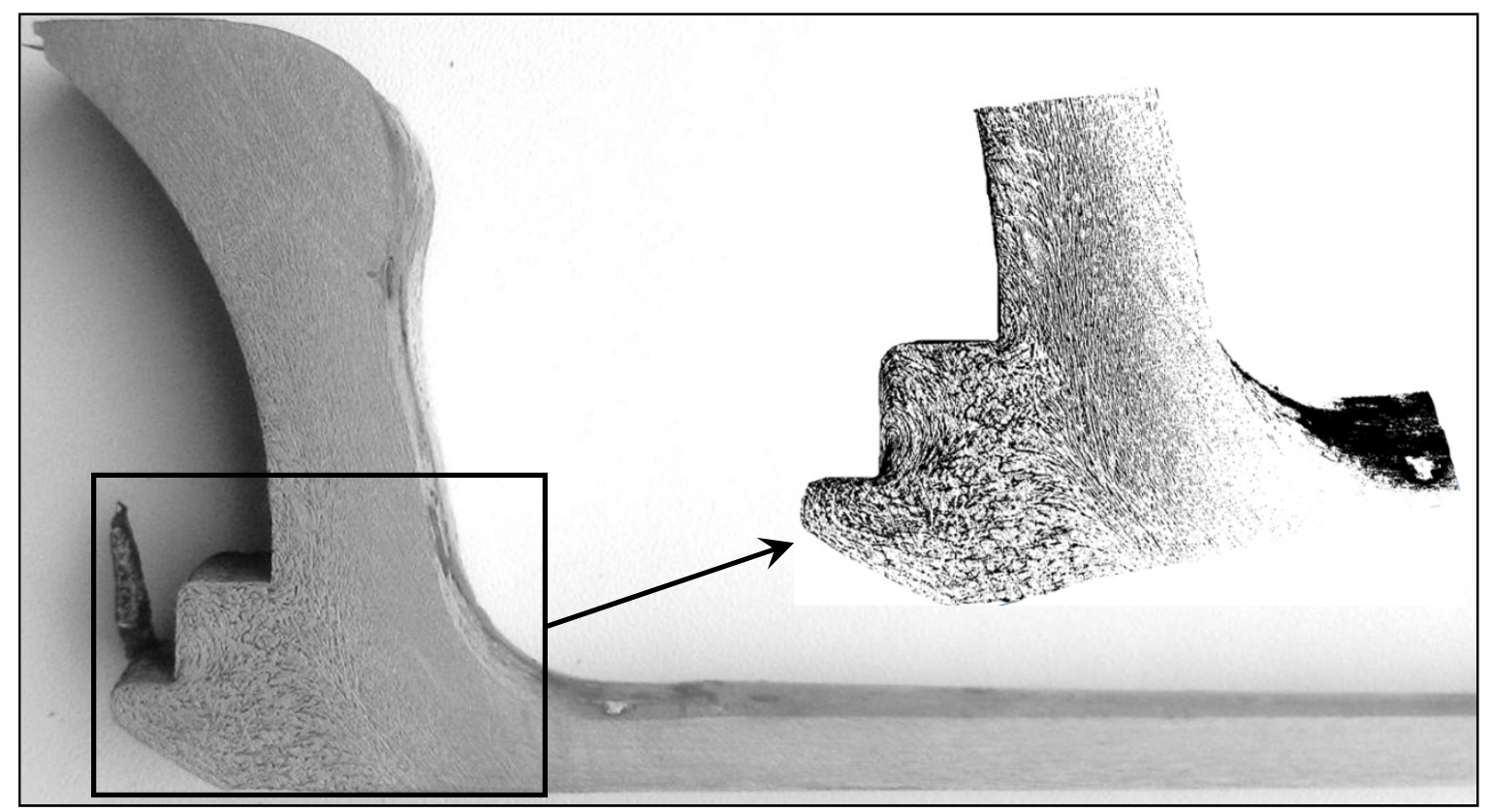

Figure 9. Macrostructure of a press residue template made of 10X13H3 steel

- the coordinate grid distribution along the length of pattern pipes (see Figures $5-7$ ) is characterized by non-uniformity. The front part of pattern pipes isn't worked out to the full through the wall thickness. At the same time, the back part is characterized by a dense structure of the coordinate grid. This as a whole enables one to implicitly judge about possible anisotropy of properties along the body of extruded pipes.

- the use of lubricants on the contact surface: a mandrel - an internal surface of the sleeve will not exert significant influence over pressing force and can be mainly applied for durability of a pressing tool and performance of qualitative characteristics of the internal surface of extruded pipes. Moreover, lubricants, designed for the internal surface of the sleeve, and consequently ensuring a separating layer between the mandrel and the sleeve, in a first place should conform to requirements for thermal properties, namely heat capacity and thermal conductivity, and only after that friction properties.

In conclusion, we should note that when maintaining dynamic and plastic conformity (Chizhikov, 1970) it is possible to use the results of the conducted research based on the CGM under production-line conditions.

\section{References}

Barichko, B. V, Kosmatskiy, Y. I., \& Akhmedyanov, A. M. (2015). The study on deformation capacity of pipe billets from hard-to-deform alloys (No. 9, Vol. 1389, pp. 68-73). Moscow: Bulletin of scientific and technological and economic information.

Barichko, B. V., Kosmatskiy, Y. I., \& Rushchits, S. V. (2013). The study on properties of centrifugal cast pipe billets of 08X18H10T steel (pp. 59-62). Moscow: Metallurgist.

Chizhikov, Y. M. (1970). The theory of similarity and simulation of metal forming processes (p. 296). Moscow: Metallurgy.

Del, G. D., \& Novikov, N. A. (1979). The method of grade grid (p. 144). Moscow: Mechanical Engineering.

Fikhtengolts, G. M. (2001). The calculus course (Vol. 2, p. 864.). Moscow: FIZMATLIT.

Gubkin, S. I. (1960). Plastic deformation of metals: in 2 vol. Physical and mechanical basics of plastic deformation (p. 376). Moscow: Metallurgy.

Kargin, V. R., \& Kargin, B. V. (2011). The basics of technological processes of metal treatment under pressure: Extrusion Unit: textbook (p. 104). Samara: Publishing House of Samara State University.

Kolmogorov, V. L. (1986). Mechanics of metal forming treatment (p. 688). Moscow: Metallurgy. 
Kosmatskiy, Y. I., Barichko, B. V., \& Voskhodov, V. B. (2014). The assessment of technological capability of producing hot-pressed pipes from the centrifugal cast shell of AISI 321 steel (No. 1, Vol. 1369, pp. 58-63). Moscow: Bulletin of scientific and technological and economic information.

Kosmatskiy, Y. I., Fokin, N. V., \& Filyaeva, E. A. (2016). The study on deformation capacity of Ti-3Al-2.5V titanium alloy and the assessment of technological capability of producing hot-pressed pipes from it (No. 2, pp. 18-22). Moscow: Titan. Titan Interstate Association.

Kosmatskiy, Y. I., Gaslenko, M. I., \& Tikhonova, M. A. (2013). Information support and control of pipe extrusion processes: textbook (p. 45). Chelyabinsk: SUSU Publishing House.

Manegin, Y. V., \& Anisimova, I. V. (1978). Glass lubrication and protective coating for hot metal working (p. 224). Moscow: Metallurgy.

Osadchy, V. Y., \& Kolikov, A. P. (2012). Production and quality of steel pipes (p. 370). Moscow: Publishing House of Moscow State Instrument Engineering and Computer Science.

Perlin, I. L. (1964). Theory of metal extrusion (p. 423). Moscow: Metallurgy.

Siebel, E. (1934). Metal working in the plastic state. Theoretical justification of metal forming processes: textbook for metallurgical institutes (p. 200). Sverdlovsk: ONTI on ferrous and non-ferrous metallurgy.

Starostin, Y. S., \& Kargin, V. R. (1983). The effectiveness of extrusion and the quality of molding (pp. 82-85). St. Petersburg: VILS.

Thomsen, E., Yang, C., \& Kobayashi, S. (1969). Mechanics of plastic deformation in metal processing (pp. 287-292). Moscow: Mechanical Engineering.

\section{Copyrights}

Copyright for this article is retained by the author(s), with first publication rights granted to the journal.

This is an open-access article distributed under the terms and conditions of the Creative Commons Attribution license (http://creativecommons.org/licenses/by/4.0/). 